\title{
Alcohol Suppresses the Electroencephalographic Response to Visual Erotic Stimuli in Young Men
}

\author{
Marisela Hernández-González , Araceli Sanz-Martin, Miguel Ángel Guevara, \\ Claudia Amezcua-Gutiérrez, Marina Ruiz Díaz \\ Instituto de Neurociencias, Universidad de Guadalajara, Guadalajara, México \\ Email: ${ }^{*}$ mariselh@cencar.udg.mx
}

Received May 13, 2012; revised June 14, 2012; accepted June 25, 2012

\begin{abstract}
Although the combination of alcohol and sex is frequently observed in human social interaction, many questions concerning alcohol's effects on the processing of sexual stimuli and brain functionality remain unanswered. Erotic films eliciting sexual arousal in humans and affect electroencephalographic (EEG) activity. This study examines the effects of alcohol on cortical EEG activity in young men while viewing an erotic film. Heterosexual males participated in an independent alcohol/placebo group protocol. Thirty-five minutes after beverage ingestion, EEGs were recorded at prefrontal, temporal and parietal derivations in three conditions: baseline, and while watching erotic and neutral films. During the observation of erotic films, only the participants who drank the placebo beverage showed a decrease in alpha1 and an increase in the fast frequencies of the prefrontal regions, as well as a decrease in inter-prefrontal synchronization in the alpha and beta bands. Alcohol suppressed the prefrontal EEG changes associated with watching erotic visual stimuli without affect the sexual arousal. EEG data show that alcohol affecting the functioning of the prefrontal cortex, which could interfere with the adequate processing of visual erotic stimuli. These findings may contribute to improving our understanding of the brain mechanisms that underlie alcohol's effects on the processing of sexual stimuli.
\end{abstract}

Keywords: Alcohol; Erotic Stimulation; Sexual Arousal; EEG Correlation; Electroencephalogram

\section{Introduction}

In human social interaction, the ingestion of alcohol has been frequently associated with feeding, parties and typical early dating $[1,2]$. Red wine is one type of alcoholic beverage that induces euphoric and relaxing effects in drinkers, which is used in many social contexts, such as sexual encounters. Basic research has established that alcohol impairs cognitive functions such as selective attention [3], cognitive control [4,5], and information processing [6]. Given that these fundamental processes lie upstream from the performance of more complex social perception tasks, alcohol also interferes with the perception and adequate interpretation of sexual cues [7].

It has been described that low and moderate doses of alcohol induce an aroused state associated with a lack of sexual inhibition [1] together with an increase in sexual arousal [8,9]; whereas high doses make sexual behavior and penile erection difficult [10]. This effect on penile erection (the main index of sexual arousal) has been attributed to alcohol's action on the prefrontal cortex (PFC), since this structure is particularly vulnerable to

${ }^{*}$ Corresponding author. acute or chronic alcohol consumption [11,12], and plays a pivotal role in the inhibition of sexual impulses [13-15], the processing of sexual motivation/aroused states [1619], and cognitive processing [20].

Several studies have demonstrated the effectiveness of erotic films in eliciting sexual arousal in humans [21-23] using both, questionnaires or verbal reports as well as objective measures (changes of the penile circumference) $[24,25]$. Associated with this sexual arousal state induced by observation of erotic films, characteristic EEG changes has been reported, such as increases in the fast frequencies and decreases in the synchronization between cortical areas of young men [26-28].

Alcohol also affects EEG activity. Schwartz and colleagues [29] have suggested that during the first $30 \mathrm{~min}-$ utes - the so-called absorption phase-alcohol produces an increase in the fast frequencies but a decrease in slow activity. However, in the ensuing early elimination phase (descending Blood Alcohol Concentration levels), this drug acts as a depressant, exercising a sedating effect associated with a reverse EEG pattern. In a previous study, similar EEG changes were reported after the ingestion of red wine in young men [30]. 
Despite considerable interest in the neural basis of alcohol effects, the question of how this drug affects brain functionality during sexual arousal has received little attention. Considering that the PFC and its connections with other cortices has been involved in the processing of motive-emotional states as well as in the alcohol effects, it is most likely that alcohol changes the EEG activity of the prefrontal, parietal and temporal cortices in young men while watching erotic films.

\section{Methods}

\subsection{Participants}

Twenty-four healthy heterosexual males aged 23 to 31 (mean, 27; $\mathrm{SE}=0.044$ ) with a mean body mass of 77.6 $\mathrm{kg}$ were voluntary participants. None had any prior history of neurological or psychiatric disorders and all were non-drug users. None were taking medication that might have influenced their EEGs. Although all subjects had experience with alcohol, they did not indulge in excessive or binge drinking (less than one drink per day). The study was approved by the Institute's Research Ethics Committee and complied with APA ethical standards. The men were only allowed to participate after giving their informed consent. They were asked to refrain from drinking any caffeine or alcohol during the $12 \mathrm{~h}$ prior to the EEG recording sessions, and were also asked to have breakfast or lunch $2 \mathrm{~h}$ beforehand. Participants attended an experimental session, where they received the placebo or red wine. The assignation of subjects to the groups was random. Those in the alcohol group $(\mathrm{AG}, \mathrm{n}=12)$ drank $4.3 \mathrm{ml} / \mathrm{kg}$ of red wine (equivalent to $0.45 \mathrm{~g} / \mathrm{kg}$ of ethanol), whereas the placebo group $(\mathrm{PG}, \mathrm{n}=12)$ drank the same dose, which was presented as wine, though they actually ingested a grape beverage with a similar flavor, color and texture to red wine, but with the alcohol removed. To give the placebo an alcoholic odor, $3 \mathrm{ml}$ of red wine were added just before it was given to the subjects. All men were asked to finish their drink within 8 minutes.

\subsection{Films}

The visual stimuli used consisted of fragments from two color films (neutral or erotic) without sound, which were presented in a random order (each for 5 minutes) on a 14" screen. The neutral stimulus was taken from "The Long Shadow" [31] and showed a man walking through a crowd; the erotic stimulus was extracted from "The Catwoman" [32], a film that shows erotic scenes and explicit sexual interaction.

\subsection{Scales}

To select only heterosexual males with no sexual dysfunctions, two scales were applied immediately upon completing the EEG recordings: the "Kinsey Scale" [33] and the "Arizona Sexual Experience Scale" (ASEX) [34]. To evaluate the degree of sexual arousal induced in the subjects during observation of the erotic film, at all participants was applied a Likert-type Sexual Arousal Scale (SAS) that was created by the authors and has been used in other studies (Figure 1) [35]. Both the selection of the neutral and erotic films and the use of the SAS scale were based on pilot studies.

\subsection{Blood Alcohol Concentration (BAC)}

A breath analyzer (Alcoscan AL-6000) was used to measure each participant's BAC. Readings were taken at the beginning of the experimental session $(5 \mathrm{~min}$ before beverage consumption), $25 \mathrm{~min}$ after ingestion (right after EEG baseline recording), and before viewing the erotic or neutral films.

\subsection{EEG Procedure}

EEG recordings were made in a sound-attenuated room at $22^{\circ} \mathrm{C}-23^{\circ} \mathrm{C}$, between 10:00 - 14:00 h. EEGs from six derivations of the International 10/20 System [36] (F3, F4, T3, T4, P3 and P4) were collected using Grass golden cup electrodes referenced to linked earlobes, with impedances kept below 10 Kohms. The EEG data were recorded using a Grass P-7 polygraph (Grass Technologies, Co., USA) with filters set at $1-30 \mathrm{~Hz}$, digitized at a

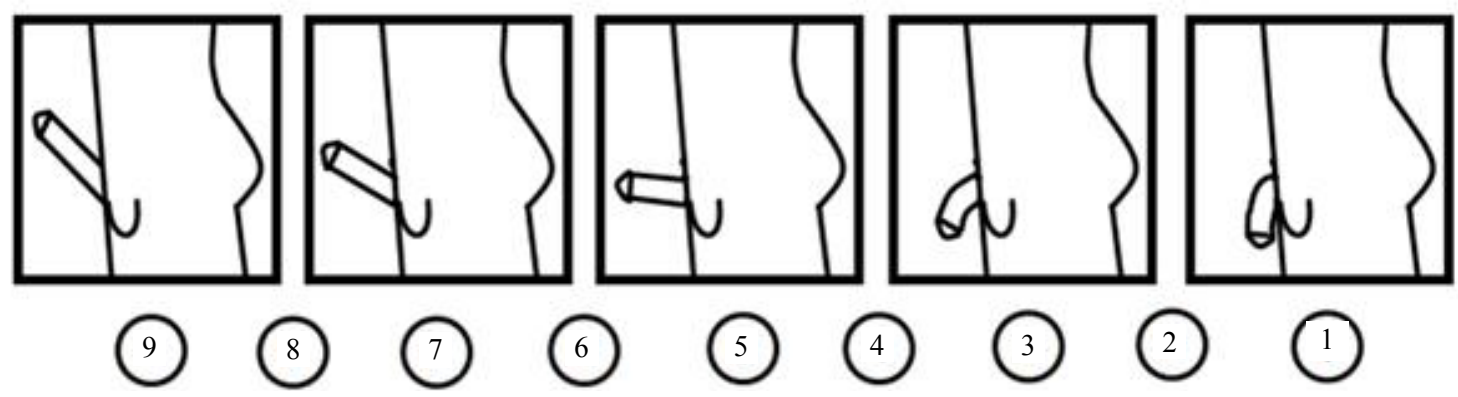

Figure 1. Sexual arousal scale (SAS). Participants had to indicate their level of subjective sexual arousal by marking circles beneath the penile images. The values of sexual arousal were graded from 1 (no sexual arousal) to 9 (maximal sexual arousal). 
sampling rate of $512 \mathrm{~Hz}$, and stored on a PC using the CAPTUSEN acquisition software [37].

All EEG recordings were made 35 min after beverage ingestion in a sound-attenuated room in three conditions, each of which lasted 5 minutes: at rest with eyes open - considered as baseline (BL) — and while watching the neutral or the erotic film. The order in which the visual stimuli were presented was counterbalanced. Between conditions, there was a 5-minute interval during which BAC was measured.

The EEG signals were analyzed off-line to eliminate saturated or artifact-contaminated epochs. Fast Fourier Transform (FFT) analyses were then applied to the artifact-free data in 2-s epoch samples, with the spectral graph ranging from $0.5-30 \mathrm{~Hz}$ at $0.5 \mathrm{~Hz}$-resolution. FFTs were performed using EEGmagic software [38] to calculate: 1) absolute power (AP), defined as the power density of each frequency band expressed in microvolts squared $(\mu \mathrm{V} 2 / \mathrm{Hz}) ; 2)$ relative power $(\mathrm{RP})$, the proportional contribution of each band to total power across 1 $30 \mathrm{~Hz}$ and; 3) correlation, the degree of functional coupling between the prefrontal and parietal or temporal cortices in each one of the six frequency bands monitored: namely, delta $(1-3.5 \mathrm{~Hz})$, theta $(4-7.75 \mathrm{~Hz})$, alpha1 $(8-10.5 \mathrm{~Hz})$, alpha2 $(11-13.5 \mathrm{~Hz})$, beta1 (14 $19.5 \mathrm{~Hz})$ and beta2 $(20-30 \mathrm{~Hz})$. Correlation values were averaged over all epochs of the same condition for each subject and pair of derivations. In order to approximate a normal distribution, the AP and RP values were transformed into logarithms and the correlation values into Fisher's z scores before commencing statistical analysis.

\subsection{Statistical Analysis}

For the statistical analysis of the EEG parameters, the baseline condition was subtracted from the neutral and erotic film conditions, respectively. To test for differences between groups (alcohol vs. placebo) and conditions (neutral vs. erotic films), split-plot ANOVAs (group $\times$ condition) were performed for each derivation and band, using EEGmagic software [38]. This analysis was also performed for the values recorded on the Kinsey, ASEX and SAS scales. Post-hoc comparisons (Tukey's test) were used to determine where differences occurred $(\mathrm{p}<$ $0.05)$.

\section{Results}

\subsection{BAC}

The average BAC value obtained at $25 \mathrm{~min}$ after alcohol ingestion was $0.035 \pm 0.061$ (mean \pm D.E.M) g/l and it remained stable throughout the subsequent measuring times. There were no significant differences among the three BAC measures.

\subsection{Scales}

The Kinsey scale showed that all participants were heterosexual, whereas the ASEX scale determined an intermediate level of sexual arousal (mean $11.875 \pm 1.98$ ) with no evidence of any sexual dysfunction. With respect to evaluations of the videos, the results of the SAS scale showed no significant difference between groups, but significant differences between the films did appear, $\mathrm{F}$ $(1,23)=71.15 ; \mathrm{p} \leq 0.0001$. Tukey's HSD tests showed that only the erotic film generated sexual arousal, in contrast to the neutral video (Table 1).

\subsection{EEG}

\subsubsection{Absolute Power}

Two main effects were obtained. For the groups factor, the alcohol group (AG) presented a decrease in AP in beta2 at $\mathrm{P} 4, \mathrm{~F}(1,22)=7.44, \mathrm{p}=0.01186$, while for the conditions factor, the erotic film was associated with a decreased AP in alpha2 at $\mathrm{P} 4, \mathrm{~F}(1,22)=4.40, \mathrm{p}=$ 0.04531 , and in beta1 at P3, $\mathrm{F}(1,22)=4.63, \mathrm{p}=0.04037$.

Some significant interactions among groups and conditions were found at F4. As Figure 2 shows, only the placebo group (PG) showed a difference between the videos, as the erotic film presented a higher AP in the beta2 compared to the neutral video at $\mathrm{F} 4, \mathrm{~F}(1,22)=5.32$, $\mathrm{p}=0.029$.

\subsubsection{Relative Power}

A main effect of groups was found, as AG showed a lower RP in the alpha2 band at P4, F $(1,22)=4.35, \mathrm{p}=$ 0.046 , as well as a tendency (not significant) to decrease the RP of beta2.

Also observed was a main effect between conditions. During the erotic stimulus, participants presented a lower alpha2 RP at F3, F(1,22) = 7.93, p = 0.0098; P3, F(1,22) $=5.53, \mathrm{p}=0.027$, and $\mathrm{P} 4, \mathrm{~F}(1,22)=5.67, \mathrm{p}=0.025$, as well as a higher delta at $\mathrm{P} 3, \mathrm{~F}(1,22)=12.96, \mathrm{p}=0.002$, and $\mathrm{P} 4, \mathrm{~F}(1,22)=9.21, \mathrm{p}=0.006$.

Interactions between groups and conditions were significant. As shown in Figure 3, only PG showed differences between the film conditions in the prefrontal areas, as the erotic video was associated with a decreased $\mathrm{RP}$ in alpha1 at $\mathrm{F} 3, \mathrm{~F}(1,22)=4.65, \mathrm{p}=0.040$, and $\mathrm{F} 4$,

Table 1. Sexual arousal values induced in the subjects of the alcohol and placebo groups during the observation of erotic and neutral films.

\begin{tabular}{ccc}
\hline Groups & Erotic film X (S. D.) & Neutral film X (S. D.) \\
\hline Alcohol & $4.417(2.193)^{*}$ & $1(0)$ \\
Placebo & $4.083(1.832)^{*}$ & $1(0)$ \\
\hline
\end{tabular}

${ }^{*} \mathrm{p} \leq 0.05$ as compared to neutral film. 


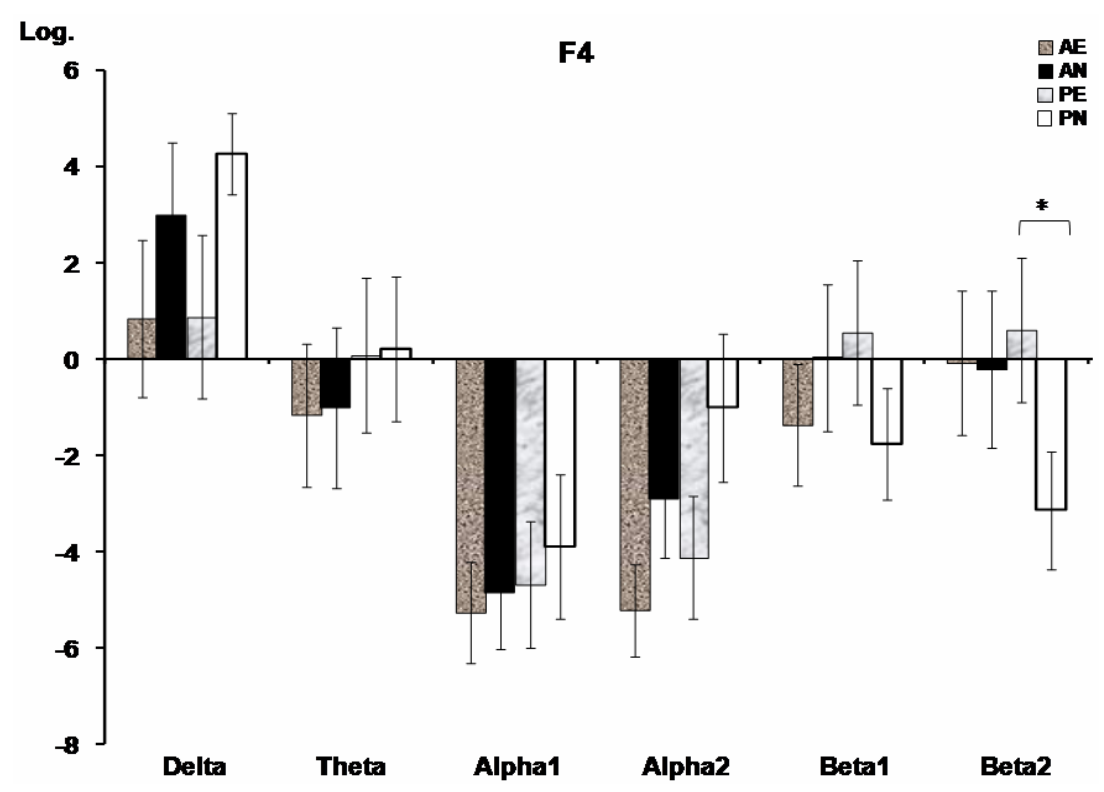

Figure 2. Prefrontal absolute power (mean $\log \pm \mathrm{SE}$ ) of the frequency bands where significant interactions between groups (alcohol, placebo) and conditions (erotic, neutral films) were found. The baseline condition was subtracted from the neutral and erotic film conditions, respectively. AE, alcohol erotic; AN, alcohol neutral; PE, placebo erotic; PN, placebo neutral. Asterisks indicate significant differences $(p<0.05)$ on the Tukey's HSD test.

$\mathrm{F}(1,22)=17.68, \mathrm{p}=0.001$, as well as with an increased RP in the betal (F4), $F(1,22)=4.72, p=0.039$, and beta2 ( $\mathrm{F} 3$ and $\mathrm{F} 4), \mathrm{F}(1,22)=4.0, \mathrm{p}=0.05 ; \mathrm{F}(1,22)=$ $7.25, \mathrm{p}=0.013$ bands, compared to the neutral movie.

\subsubsection{Inter-Hemispheric Correlation}

In the ANOVA of this parameter, only a main effect of conditions appeared, with the erotic film producing a lower inter-prefrontal correlation than the neutral one in alpha1, $\mathrm{F}(1,22)=7.83, \mathrm{p}=0.01019$, alpha2 $\mathrm{F}(1,22)=$ $8.07, \mathrm{p}=0.00929$, and beta1 $\mathrm{F}(1,22)=6.23, \mathrm{p}=0.01949$. Also, as the interaction between groups and conditions illustrated, this effect was only evident in the PG of alpha2 $\mathrm{F}(1,22)=6.06, \mathrm{p}=0.02102$, and beta1 $\mathrm{F}(1,22)=$ $5.69, \mathrm{p}=0.02470$ (Figure 4).

\subsubsection{Intra-Hemispheric Correlation}

There was a main effect of conditions in the theta band, where the F3-P3 correlation was higher during erotic video than during the neutral one $\mathrm{F}(1,22)=5.06, \mathrm{p}=$ 0.03299 .

\section{Discussion}

The data obtained show that a moderate dose of alcohol suppresses the prefrontal EEG changes associated with observing visual erotic stimuli in young men, though without affecting the level of sexual arousal they reported.

Previous studies have shown that alcohol does not affect subjective evaluations of sexual arousal $[24,25,39]$, thus, a possible explanation is that the alcohol administered did not affect the men's self-perceptions of sexual arousal, so that the participants in AG had similar perceptions of their subjective sexual arousal to those of the men in PG.

Additionally, some studies have suggested that the fact that subject's believe they are drinking an alcoholic beverage, even with no real alcohol administration, can increase subjective sexual arousal $[8,24,40]$. In our study, participants in both groups believed they had ingested red wine. This expectation could affect subjective sexual arousal in the same way in both groups, such that no differences emerged between them.

Although no differences were obtained in the sexual arousal level between groups, clear EEG differences between the erotic and neutral visual stimuli were observed. Only the participants who drank the placebo beverage showed a decrease in alphal and an increase in the fast frequencies (beta1 and beta2 bands) in the prefrontal regions, together with a decrease in the inter-prefrontal synchronization in the alpha and beta bands during observation of the erotic film. These EEG changes have traditionally been associated with an activated state [41], cortical arousal [42,43] and increased attention [44]. Thus, it is probable that the prefrontal EEG changes that subjects in PG prvesented are associated with the higher attention they manifested while watching the erotic stimuli.

On the other hand, and regardless of the kind of film viewed, in this study subjects in AG presented lower fast 

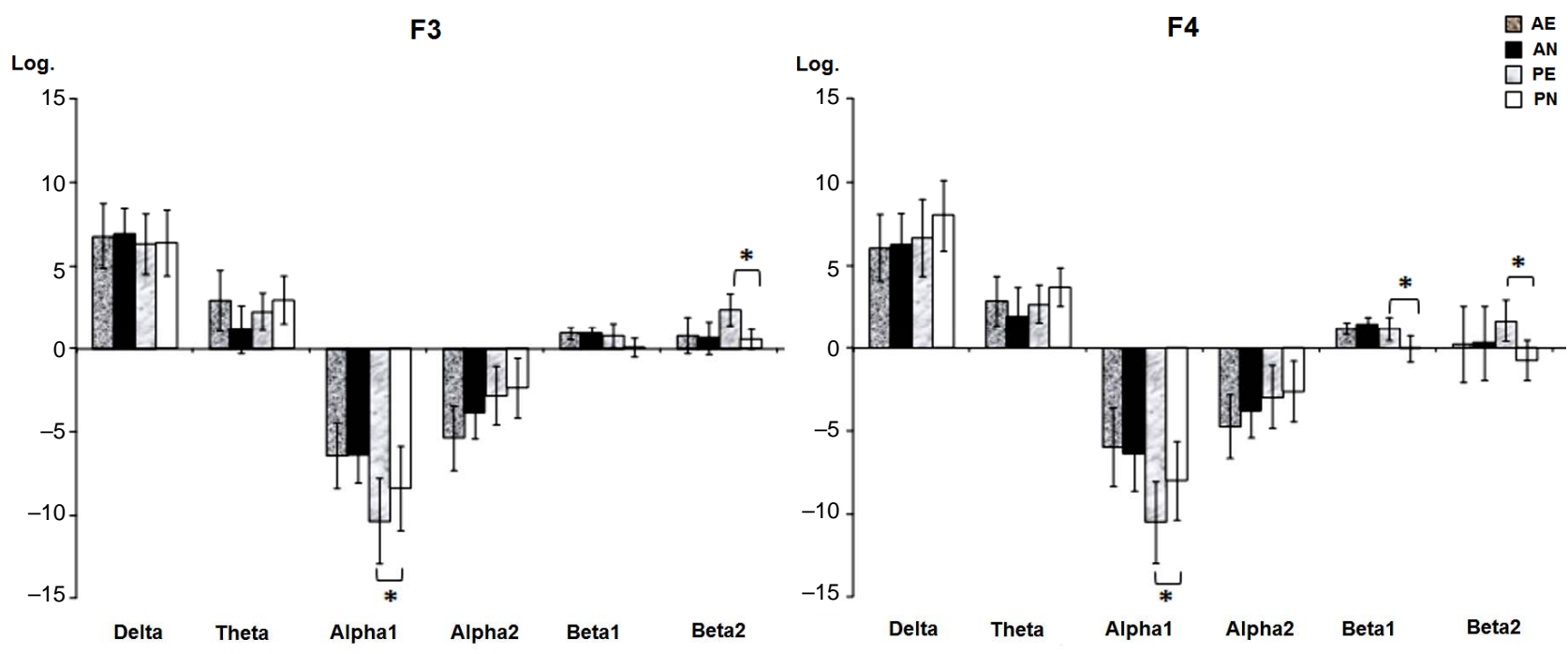

Figure 3. Prefrontal relative power (mean $\log \pm \mathrm{SE}$ ) of the frequency bands where significant interactions between groups (alcohol, placebo) and conditions (erotic, neutral films) were found. The baseline condition was subtracted from the neutral and erotic film conditions, respectively. AE, alcohol erotic; AN, alcohol neutral; PE, placebo erotic; PN, placebo neutral. Asterisks indicate significant differences $(p<0.05)$ on the Tukey's HSD test.

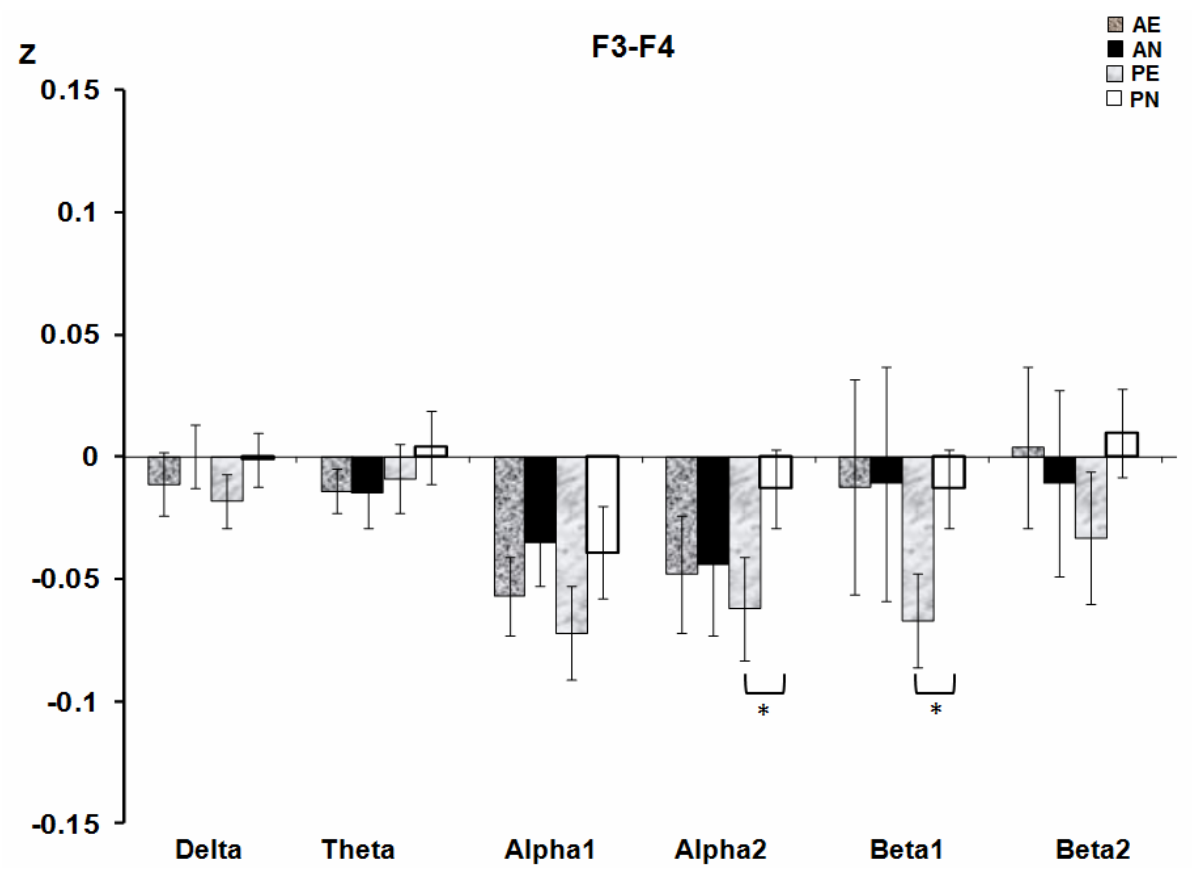

Figure 4. Inter-prefrontal correlation (mean $\mathrm{Z} \pm \mathrm{SE}$ ) of the frequency bands where significant interactions between groups (alcohol, placebo) and conditions (erotic, neutral films) were found. The baseline condition was subtracted from the neutral and erotic film conditions, respectively. AE, alcohol erotic; AN, alcohol neutral; PE, placebo erotic; PN, placebo neutral. Asterisks indicate significant differences $(p<0.05)$ on the Tukey's HSD test.

frequencies in the right parietal cortex, a characteristic EEG pattern of the descending phase of BAC. It is well known that the parietal lobes play a fundamental roll in orientation and selective attention [45], that beta activity has been associated with vigilance and selective attention $[18,46]$, and that a decrease in this band has been observed in psychopathological states, such as attention deficit disorder [47]. Alpha activity, especially in alpha2, has also been related to attention $[48,49]$. Attention is a cognitive process that has been shown to be sensitive to the effects of alcohol, so our EEG data are congruent with the findings of several other studies that have demonstrated that alcohol has a deleterious effect on attention $[3,50]$, and reduces cortical arousal [51]. 
Alcohol intoxication disrupts cognitive capabilities and may thereby compromise the ability to adequately process erotic stimuli. Thus, the possible effect of alcohol on EEG activity in the prefrontal cortex could be associated with deficient processing of the visual stimuli. It is well known that alcohol is a depressor of the central nervous system and that the prefrontal cortex is one of the more sensitive cortical areas to its effects. Moreover, the significant role that the prefrontal cortex plays in the processing of relevant stimuli (such as erotic films) has been reported [17]. Thus, it is also possible that alcohol could affect the adequate functioning of this cortical area such that the characteristic prefrontal EEG changes associated to watch visual erotic stimuli were not observed. In other words, it is probable that alcohol impedes the adequate processing of each visual stimulus, causing the prefrontal cortices to function similarly during the observation of both the neutral and the erotic films, though without affecting self-perceptions of sexual arousal in the subjects in AG.

Previous evidence based on event-related brain potentials (ERPs) suggests that biologically relevant stimuli, like erotic ones, receive prioritized processing in the attentional neural network. Erotic visual stimuli elicit a larger positive wave that may begin at $185 \mathrm{~ms}$ poststimulus and continue to $300-700 \mathrm{~ms}[16,52,53]$. In the present study, regardless of the beverage ingested, the erotic film generated an increase in delta activity, but a decrease in the alpha 2 and beta 1 bands in the parietal lobes. These parietal EEG changes could be associated with a regional reduction of cortical arousal necessary for the attention to internal sensations that sexual arousal induces. Previous papers have proposed that an increase in delta and alpha2 activity in the temporal-parietal area during the performance of mental tasks might be associated with attention to internal processing [54], internal speech, storage, and the rehearsal of verbal working memory [55].

Similar EEG parietal changes were found by Dimpfel et al. [56], who observed an increase in delta activity but a decrease in alpha activity while subjects viewed erotic films.

Additionally, we found, mainly in PG, that erotic stimuli produced a lower inter-frontal correlation. This hemispheric asymmetry associated with the sexual arousal induced by viewing the erotic film agrees with data from a previous experiment that also found a decreased inter-frontal correlation during the observation of erotic pictures [28]. Our data on absolute power support this decreased correlation, as only the right frontal lobe presented an increase in the beta 2 band. This asymmetry could be a consequence of hemispheric differences in the processing of sexual stimuli and sexual arousal. In this instance, studies of EEGs have demonstrated that the sexual arousal state in men is associated mainly with an activation of the right hemisphere [26,27,57], though neuroimaging studies support the involvement of certain left hemisphere regions in sexual arousal $[58,59]$.

Finally, the erotic video increased left frontal-parietal synchronization in the theta band, which could be related to an emotional response to this stimulus. Previous studies have shown that the synchronization between the left anterior and posterior cortices increased during positive emotional states, especially in the theta [60] and alpha bands [61]. This may be consistent with the findings on EEG during orgasm reported by Cohen et al. [26], who observed an increase in theta activity. In addition, during sexual arousal, Tucker et al. [57] observed an increased synchronization among cortical regions in the theta and beta 2 bands, though this rise appeared only in the right hemisphere.

In conclusion, alcohol suppressed the prefrontal EEG changes related to the observation of erotic visual stimuli, though without affecting the sexual arousal they generated. The participants who drank alcohol showed EEG changes associated with low attention, but no EEG changes during erotic stimulation; whereas the subjects that drank the placebo beverage showed clear EEG differences between the erotic and neutral film conditions. This deleterious effect of alcohol on the adequate functioning of the prefrontal cortex could interfere with the perception and adequate interpretation of erotic stimuli in young men.

Additional research is required, particularly concerning the objective measures of the penile erection while the subjects watch the erotic films in order to discern if, the decreased inter-prefrontal correlation values are related to increased sexual arousal and, hence, if it EEG changes can be used as index of the sexual activation in young men.

\section{REFERENCES}

[1] M. L. Cooper and H. K. Orcutt, "Drinking and Sexual Experience on First Dates among Adolescents," Journal of Abnormal Psychology, Vol. 106, No. 2, 1997, pp. 191202. doi:10.1037/0021-843X.106.2.191

[2] A. Prince and A. L. Bernard, "Alcohol Use and Safer Sex Behaviors of Students at a Commuter University," Journal of Alcohol and Drug Education, Vol. 43, No. 2, 1998, pp. 1-19.

[3] T. Duka and J. Townshend, "The Priming Effect of Alcohol Pre-Load on Attentional Bias to Alcohol-Related Stimuli," Psychopharmacology, Vol. 176, No. 3-4, 2004, pp. 353-361. doi:10.1007/s00213-004-1906-7

[4] B. D. Bartholow, M. Pearson, K. J. Sher, L. C. Wieman, M. Fabiani and G. Gratton, "Effects of Alcohol Consumption and Alcohol Susceptibility on Cognition: A Psychophysiological Examination," Biological Psychology, 


\section{doi:10.1016/S0301-0511(03)00108-X}

[5] M. T. Fillmore, C. A. Marczinski and A. M. Bowman, "Acute Tolerance to Alcohol Effects on Inhibitory and Activational Mechanisms of Behavioral Control," Journal of Studies on Alcohol, Vol. 66, No. 5, 2005, pp. 663672.

[6] T. A. Schweizer, M. Vogel-Sprott, J. Danckert, E. A. Roy, A. Skakum and C. E. Broderick, "Neuropsychological Profile of Acute Alcohol Intoxication during Ascending and Descending Blood Alcohol Concentrations," Neuropsychopharmacology, Vol. 31, No. 6, 2006, pp. 13011309.

[7] C. Farris, T. A. Treat and R. J. Viken, "Alcohol Alters Men's Perceptual and Decisional Processing of Women's Sexual Interest," Journal of Abnormal Psychology, Vol. 119, No. 2, 2010, pp. 427-432. doi:10.1037/a0019343

[8] W. H. George and G. A. Marlatt, "The Effects of Alcohol and Anger on Interest in Violence, Erotica, and Deviance," Journal of Abnormal Psychology, Vol. 95, No. 2, 1986, pp. 150-158. doi:10.1037/0021-843X.95.2.150

[9] W. H. George and J. Norris, "Alcohol, Disinhibition, Sexual Arousal, and Deviant Sexual Behaviour," Alcohol Health \& Research World, Vol. 15, No. 2, 1991, pp. 133138.

[10] G. M. Farkas and R. C. Rosen, "Effect of Alcohol on Elicited Male Sexual Response," Journal of Studies on Alcohol, Vol. 37, No. 3, 1976, pp. 265-272.

[11] P. N. S. Hoaken, P. R. Giancola and R. O. Pihl, "Executive Cognitive Functions as Mediators of Alcohol-Related Aggression," Alcohol and Alcoholism, Vol. 33, No. 1, 1998, pp. 47-54. doi:10.1093/oxfordjournals.alcalc.a008347

[12] H. F. Moselhy, G. Georgiou and A. Kahn, "Frontal Lobe Changes in Alcoholism: A Review of the Literature," Alcohol and Alcoholism, Vol. 36, No. 5, 2001, pp. 357-368. doi:10.1093/alcalc/36.5.357

[13] M. Beauregard, J. Levesque and P. Bourgouin, "Neural Correlates of Conscious Self-Regulation of Emotion," Journal of Neuroscience, Vol. 21, No. 18, 2001, p. 165.

[14] J. F. Davis, M. Loos, A. R. Di Sebastiano, J. L. Brown, M. N. Lehman and L. M. Coolen, "Lesions of the Medial Prefrontal Cortex Cause Maladaptive Sexual Behavior in Male Rats," Biological Psychiatry, Vol. 67, No. 12, 2010, pp. 1199-1204. doi:10.1016/j.biopsych.2009.12.029

[15] D. Knoch and E. Fehr, "Resisting the Power of Temptations: The Right Prefrontal Cortex and Self-Control," Annals of the New York Academy of Science, Vol. 1104, 2007, pp. 123-134. doi:10.1196/annals.1390.004

[16] A. P. Anokhin, S. Golosheykin, E. Sirevaag, S. Kristjansson, J. W. Rohrbaugh and A. C. Heath, "Rapid Discrimination of Visual Scene Content in the Human Brain," Brain Research, Vol. 1093, No. 1, 2006, pp. 167-177. doi:10.1016/j.brainres.2006.03.108

[17] J. Leon-Carrion, J. F. Martin-Rodriguez, J. Damas-Lopez, K. Pourrezai, K. Izzetoglu, J. M. Barrosoy Martin and M. R. Dominguez-Morales, "A Lasting Post-Stimulus Activation on Dorsolateral Prefrontal Cortex Is Produced
When Processing Valence and Arousal in Visual Affective Stimuli," Neuroscience Letters, Vol. 422, No. 3, 2007, pp. 147-152. doi:10.1016/j.neulet.2007.04.087

[18] A. Agmo, A. Villalpando, Z. Picker and H. Fernandez, "Lesions of the Medial Prefrontal Cortex and Sexual Behavior in the Male Rat," Brain Research, Vol. 696, No. $1-2,1995$, pp. 177-186. doi:10.1016/0006-8993(95)00852-H

[19] M. Hernández-González, C. A. Prieto-Beracoechea, M. Arteaga-Silva and M. A. Guevara, "Different Functionality of the Medial and Orbital Prefrontal Cortex during a Sexually Motivated Task in Rats," Physiology and Behavior, Vol. 90, No. 2-3, 2007, pp. 450-458. doi:10.1016/j.physbeh.2006.10.006

[20] J. M. Fuster, "The Prefrontal Cortex: Anatomy, Physiology and Neurophysiology of the Frontal Lobe," Lippincott-Raven Publishers, Philadelphia, 1997.

[21] N. G. Exton, T. Truong, M. S. Exton, S. A. Wingenfeld, N. Leygarf, B. Saller, U. Hartmannn and M. Schedlowski, "Neuroendrocrine Responses to Film-Induced Sexual Arousal in Men and Women," Psychoneuroendocrinology, Vol. 25, No. 2, 2000, pp. 187-199. doi:10.1016/S0306-4530(99)00049-9

[22] E. Koukounas and M. McCabe, "Sexual and Emotional Variables Influencing Sexual Response to Erotica: A Psychopliysiological Investigation," Archives of Sexual Be- havior, Vol. 30, No. 4, 2001, pp. 393-408. doi:10.1023/A:1010261315767

[23] E. Koukounas and M. McCabe, "Sexual and Emotional Variables Influencing Sexual Response to Erotica," Behaviour Research and Therapy, Vol. 35, No. 3, 1997, pp. 221-231. doi:10.1016/S0005-7967(96)00097-6

[24] D. W. Briddell, D. C. Rimm, G. R. Caddy, G. Krawitz, D. Sholis and R. J. Wunderlin, "Effects of Alcohol and Cognitive Set on Sexual Arousal to Deviant Stimuli," Journal of Abnormal Psychology, Vol. 87, No. 4, 1978, pp. 418430. doi:10.1037/0021-843X.87.4.418

[25] W. H. George, K. C. Davis, J. Norris, J. R. Heiman, R. L. Schacht, S. A. Stoner and K. F. Kajumulo, "Alcohol and Erectile Response: The Effects of High Dosage in the Context of Demands to Maximize Sexual Arousal," Experimental and Clinical Psychopharmacology, Vol. 14, No. 4, 2006, pp. 461-470. doi:10.1037/1064-1297.14.4.461

[26] H. D. Cohen, R. C. Rosen and L. Goldstein, "Electroencephalographic Laterality Changes during Human Sexual Orgasm," Archives of Sexual Behavior, Vol. 5, No. 3, 1976, pp. 189-199. doi:10.1007/BF01541370

[27] A. S. Cohen, R. C. Rosen and L. Goldstein, "EEG Hemispheric Asymmetry during Sexual Arousal: Psychophysiological Patterns in Responsive, Unresponsive, and Dysfunctional Men," Journal of Abnormal Psychology, Vol. 94, No. 4, 1985, pp. 580-590. doi:10.1037/0021-843X.94.4.580

[28] M. Hernández-González, C. Amezcua, A. Sanz-Martin, K. Rivera-Sánchez and M. A. Guevara, "Sexual Arousal Decreases the Functional Syncronization between Cortical Areas in Young Men," Journal of Sex \& Marital Therapy, 2012, in press. 
[29] E. Schwartz, P. Kielholz, L. Goldberg, U. Gilsdorf, M. Hofstetter, D. Ladewig, P. C. Miest, G. Reggiani and R. Richter, "Alcohol-Induced Biphasic Background and Stimulus-Elicited EEG Changes in Relation to Blood Alcohol Levels," International Journal of Clinical Pharmacology, Therapy and Toxicology, Vol. 19, No. 3, 1981, pp. 102-111.

[30] A. Sanz-Martin, M. A. Guevara, C. Amezcua, G. Santana and M. Hernández-González, "Effects of Red Wine on the Electrical Activity and Functional Coupling between Prefrontal-Parietal Cortices in Young Men," Appetite, Vol. 57, No. 1, 2011, pp. 84-93. doi:10.1016/j.appet.2011.04.004

[31] V. Zsigmond, "The Long Shadow," Israel, 1992.

[32] J. Leslie, "The Catwoman," USA, 1988.

[33] A. C. Kinsey, W. R. Pomeroy and C. E. Martin, "Sexual Behavior in the Human Male," Saunders, Philadelphia, 1948.

[34] C. A. McGahuey, A. J. Gelenberg, C. A. Laukes, F. A. Moreno, P. L. Delgado, K. M. McKnight and R. Manber, "The Arizona Sexual Experience Scale (ASEX): Reliability and Validity," Journal of Sex \& Marital Therapy, Vol. 26, No. 1, 2000, pp. 25-40. doi: $10.1080 / 009262300278623$

[35] M. Ruiz-Díaz, M. Hernández-González, M. A. Guevara, C. Amezcua and A. Ågmo, "Prefrontal EEG Correlation during Tower of Hanoi and WCST Performance: Effect of Emotional Visual Stimuli," Journal of Sexual Medicine, 2012, in press. doi:10.1111/j.1743-6109.2012.02782.x

[36] H. H. Jasper, "Report of the Committee on Methods of Clinical Examination in Electroencephalography," Electroencephalography and Clinical Neurophysiology, Vol. 10, 1958, pp. 370-371. doi:10.1016/0013-4694(58)90053-1

[37] M. A. Guevara, J. Ramos, M. Hernández-González and M. Corsi-Cabrera, "Captusen: A System for the Computerized Acquisition of EEG and Event-Related Potentials," Mexican Journal of Psychology, Vol. 17, No. 1, 2000, p. 77.

[38] M. A. Guevara and M. Hernández-González, "EEGMAGIC: Program to Analyze Electroencephalographic Signals," Mexican Journal of Biomedical Engineering, Vol. 30, No. 1, 2009, pp. 41-53.

[39] D. W. Briddell and G. T. Wilson, "Effects of Alcohol and Expectancy Set on Male Sexual Arousal," Journal of Abnormal Psychology, Vol. 85, No. 2, 1976, pp. 225-234. doi:10.1037/0021-843X.85.2.225

[40] D. B. Abrams and G. T. Wilson, "Alcohol, Sexual Arousal, and Self-Control," Journal of Personality and Social Psychology, Vol. 45, No. 1, 1983, pp. 188-198. doi:10.1037/0022-3514.45.1.188

[41] J. T. Coult, "Neural Correlates of Attention and Arousal: Insights from Electrophysiology, Functional Neuroimaging and Psychopharmacology," Progress in Neurobiology, Vol. 55, No. 4, 1998, pp. 343-361. doi:10.1016/S0301-0082(98)00011-2

[42] E. Neidermeyer, "The Normal EEG of the Waking Adult," In: E. Neidermeyer and F. L. Da Silva, Eds., Electroe- ncephalography: Basic Principles, Clinical Applications, and Related Fields, 4th Edition, Lippincott Williams \& Wilkins, Philadelphia, 1999, pp. 149-173.

[43] J. L. Andreassi, "Psychophysiology: Human Behavior \& Physiological Response," Lawrence Erlbaum Associates, Inc., Mahwah, 2000.

[44] J. Ramos-Loyo, A. A. Gonzalez-Garrido, C. Amezcua and M. A. Guevara, "Relationship between Resting Alpha Activity and the ERPs Obtained during a Highly Demanding Selective Attention Task," International Journal of Psychophysiology, Vol. 54, No. 3, 2004, pp. 251-262. doi:10.1016/j.ijpsycho.2004.05.008

[45] M. I. Posner and M. E. Raichle "Images of Mind," 2nd Edition, Scientific American Library, New York, 1997.

[46] A. Wrobel, "Beta Activity: A Carrier for Visual Attention," Acta Neurobiologiae Experimentalis, Vol. 60, No. 2, 2000, pp. 247-260.

[47] M. M. Lansbergen, M. Arns, M. van Dongen-Boomsma, D. Spronk and J. K. Buitelaar, "The Increase in Theta/ Beta Ratio on Resting-State EEG in Boys with AttentionDeficit/Hyperactivity Disorder Is Mediated by Slow Alpha Peak Frequency," Progress in Neuropsychopharmacology \& Biological Psychiatry, Vol. 35, No. 1, 2011, pp. 47-52. doi:10.1016/i.pnpbp.2010.08.004

[48] K. M. Spencer and J. Polich, "Poststimulus EEG Spectral Analysis and P300: Attention, Task, and Probability," Psychophysiology, Vol. 36, No. 2, 1999, pp. 220-232. doi:10.1111/1469-8986.3620220

[49] J. C. Shaw, "Intention as a Component of the AlphaRhythm Response to Mental Activity," International Journal of Psychophysiology, Vol. 24, No. 1-2, 1996, pp. 7-23. doi:10.1016/S0167-8760(96)00052-9

[50] J. J. Curtin, C. J. Patrick, A. R. Lang, J. T. Cacioppo and N. Birbaumer, "Alcohol Effects Emotion through Cognition," Psychological Science, Vol. 12, No. 6, 2001, pp. 527-531. doi:10.1111/1467-9280.00397

[51] C. Ehlers, T. L. Wall and M. A. Schuckit, "EEG Spectral Characteristics Following Ethanol Administration in Young Man," Electroencephalography and Clinical Neurophysiology, Vol. 73, No. 3, 1989, pp. 179-187. doi:10.1016/0013-4694(89)90118-1

[52] J. J. van Lankveld and F. T. Smulders, "The Effect of Visual Sexual Content on the Event-Related Potential," Biological Psychology, Vol. 79, No. 2, 2008, pp. 200-208. doi:10.1016/j.biopsycho.2008.04.016

[53] K. E. Briggs and F. H. Martin, "Affective Picture Processing and Motivational Relevance: Arousal and Valence Effects on ERPs in an Oddball Task," International Journal of Psychophysiology, Vol. 72, No. 3, 2009, pp. 299. 306. doi:10.1016/j.ijpsycho.2009.01.009

[54] T. Harmony, T. Fernandez, J. Silva, J. Bernal, L. DiazComas, A. Reyes, E. Marosi and M. Rodriguez, "EEG Delta Activity: An Indicator of Attention to Internal Processing during Performance of Mental Tasks," International Journal of Psychophysiology, Vol. 24, No. 1-2, 1996, pp. 161-171. doi:10.1016/S0167-8760(96)00053-0

[55] T. Harmony, T. Fernández, J. Silva, J. Bosch, P. Valdés, A. Fernández-Bouzas, L. Galan, E. Aubert and D. Rodri- 
guez, "Do Specific EEG Frequencies Indicate Different Processes during Mental Calculation?" Neuroscience Letters, Vol. 266, No. 1, 1999, pp. 25-28. doi:10.1016/S0304-3940(99)00244-X

[56] W. Dimpfel, W. Wedekind and I. Keplinger, "Gender Difference in Electrical Brain Activity during Presentation of Various Film Excerpts with Different Emotional Content," European Journal of Medical Research, Vol. 8, No. 5, 2003, pp. 192-198.

[57] D. M. Tucker and S. L. Dawson, "Asymmetric EEG Changes as Method Actors Generated Emotions," Biological Psychology, Vol. 19, No. 1, 1984, pp. 63-75. doi:10.1016/0301-0511(84)90011-5

[58] M. Bocher, R. Chisin, Y. Parag, N. Freedman, Y. Meir Weil, H. Lester, E. Mishani and O. Bonne, "Cerebral Activation Associated with Sexual Arousal in Response to a Pornographic Clip: A 15O-H2O PET Study in Hetero- sexual Men," NeuroImage, Vol. 14, No. 1, 2001, pp. 105117. doi:10.1006/nimg.2001.0794

[59] S. T. Hamann, R. A. Herman, C. L. Nolan and K. Wallen, "Men and Women Differ in Amygdale Response to Visual Sexual Stimuli," Nature Neroscience, Vol. 7, 2004, pp. 411-416. doi:10.1038/nn1208

[60] B. A. Arnow, J. E. Desmond, L. L. Banner, G. H. Glover, A. Solomon, M. L. Polan, T. F. Lue and S. W. Atlas, "Brain Activation and Sexual Arousal in Healthy, Heterosexual Males," Brain, Vol. 125, No. 5, 2002, pp. 10141023. doi:10.1093/brain/awf108

[61] E. O. Flores-Gutiérrez, J. L. Díaz, F. A. Barrios, M. A. Guevara, Y. Del Río-Portilla, M. Corsi-Cabrera and E. O. Flores-Gutiérrez, "Differential Alpha Coherence Hemispheric Patterns in Men and Women during Pleasant and Unpleasant Musical Emotions," International Journal of Psychophysiology, Vol. 71, No. 1, 2009, pp. 43-49. 